\title{
In-Hospital and Long-Term outcomes after Open-Heart Surgery in Turkish Octogenarians: a Single-Center Study
}

\author{
Mehmet Aksüt ${ }^{1}$, MD; Deniz Günay ${ }^{1}$, MD; Tanıl Özer ${ }^{1}$, MD; Özge Altaş Yerlikhann ${ }^{1}$, MD; Emre Selçuk ${ }^{2}$, MD; Mehmet \\ Kaan Kırali', MD
}

DOI: $10.21470 / 1678-9741-2020-0013$

\begin{abstract}
Objective: We aimed to analyze the early and long-term results of open-heart surgery in Turkish patients aged 80 years or older who were operated on at our center.

Methods: All patients aged $\mathbf{8 0}$ years or older who underwent surgery between January 2000 and December 2013 at a high-level heart center were included in the study. The in-hospital data of study patients were obtained from the electronic database and from the hospital files. Survival data were analyzed as a long-term outcome.

Results: A total of 245 patients aged $80-93$ years were evaluated in the study. The patients were followed up $5.4 \pm 3.7$ years after open-heart surgery. In-hospital mortality rates were $10 \%$ in elective cases and $15.1 \%$ overall. Age $\geq 85$ years, chronic kidney disease,
\end{abstract}

chronic obstructive pulmonary disease, and emergency surgery were independent predictors of in-hospital mortality. The median survival time was found to be $4.4 \pm 0.3$ years for all participants. The long-term survival of patients who underwent emergency cardiac surgery was significantly lower than that of elective patients (log-rank $<0.001$ ).

Conclusion: Octogenarians have satisfactory long-term outcomes after open-heart surgery when operated electively. On the other hand, patients operated under emergency conditions have worse inhospital outcomes and long-term follow-up results.

Keywords: Aged, 80 and over. Cardiac Surgical Procedures. Elective Surgical Procedures. Emergency Service, Hospital. Follow-Up Studies.

\begin{tabular}{ll}
\hline \multicolumn{2}{l}{ Abbreviations, acronyms \& symbols } \\
\hline CABG & $=$ Coronary artery bypass graft \\
CKD & $=$ Chronic kidney disease \\
CKD-EPI & $=$ Chronic Kidney Disease Epidemiology Collaboration \\
COPD & $=$ Chronic obstructive pulmonary disease \\
LVEF & $=$ Left ventricular ejection fraction \\
SPSS & $=$ Statistical Package for the Social Sciences \\
\hline
\end{tabular}

\section{INTRODUCTION}

The number of people over 80 years old in Turkey has gradually increased, in line with worldwide statistics. From 60,000 in 1950, it reached up to 900,000 in $2015^{[1]}$. The worldwide cardiovascular disease prevalence is $40 \%$ among this age group;

'Cardiovascular Surgery Department, Kartal Kosuyolu Research and Education Hospital, Istanbul, Turkey.

${ }^{2}$ Cardiovascular Surgery Department, Medical Faculty of Bezmialem Vakif University, Istanbul, Turkey.

This study was carried out at the Department Cardiovascular Surgery, Kartal Kosuyolu Research and Education Hospital, Kartal, İstanbul, Turkey. however, studies carried out in Turkey indicate that this ratio ranges from $13 \%$ to $23 \%{ }^{[2-6]}$.

Studies carried out in developed countries have shown that early and long-term outcomes of open-heart surgery are successful in this high-risk patient group ${ }^{[7-13]}$. Nevertheless, the number of studies analyzing the outcomes of open-heart surgery in the Turkish octogenarian population is inadequate. A few studies have been conducted in small patient groups; the early and mid-term outcomes of these patients were analyzed, and worse outcomes were reported when compared to those in developed countries ${ }^{[14,15]}$

According to current data from the Turkish Statistical Institute, however, the life expectancy of an 80-year-old Turkish person is 8 years on average, similar to that of a person of the same age in developed countries ${ }^{[16]}$. To overcome these contradictions, we aimed to analyze the long-term survival of Turkish octogenarians

Correspondence Address:

Mehmet Aksüt

(iD) https://orcid.org/0000-0002-0280-7890

Cardiovascular Surgery Department

Kartal Kosuyolu Research and Education Hospital

Denizer Caddesi Cevizli Kavşağı, n 2 - Cevizli, Kartal, Istanbul, Turkey - Zip code: 34865 E-mail: bbmaksut@yahoo.com 
who have undergone open-heart surgery with a larger group of patients.

\section{METHODS}

\section{Study Sample}

The present study aimed to evaluate the data of all octogenarian patients who underwent open heart surgery at the study center between January 2000 and December 2013. The overall survival results of all patients were obtained from the national database. Therefore, data from 245 patients were analyzed in this study. The Institutional Ethics Committee approved the study protocol. The study followed the principles of the Declaration of Helsinki.

\section{Variables}

Hypertension was defined as the active use of antihypertensive drugs or documentation of blood pressure $>140 / 90 \mathrm{mmHg}$. Diabetes mellitus was defined as fasting plasma glucose levels $>126 \mathrm{mg} / \mathrm{dl}$, a glucose level $>200 \mathrm{mg} / \mathrm{dl}$ in any measurement, or active use of antidiabetic drugs. Chronic kidney disease (CKD) was defined as estimated glomerular filtration rate $<60$ $\mathrm{mL} / \mathrm{min} / 1.73 \mathrm{~m}^{2}$. The estimated glomerular filtration rate was calculated for each patient according to the Chronic Kidney Disease Epidemiology Collaboration (CKD-EPI) equation. Chronic obstructive pulmonary disease (COPD) was defined as the active use of bronchodilator drugs or a forced expiratory volume in 1 second of $<80 \%$.

\section{Statistical Analysis}

The distribution of continuous variables was evaluated using the Kolmogorov-Smirnov or Shapiro-Wilk tests. Categorical variables were presented as counts and frequencies; continuous variables as mean \pm standard deviation and minimum-maximum values. Chi-square test or Fisher's exact test was used for comparison between categorical variables. Student's t-test or Mann-Whitney $U$ test was used to compare continuous variables. Survival assessment was analyzed by Kaplan-Meier survival analysis, and the log-rank test was used for comparisons. Independent predictors for in-hospital mortality were analysed with binary logistic regression. First, the univariate logistic regression model was established with well-defined operative risk factors. Likewise, every variable was included in the multivariate analyses and the SPSS software version 23.0 (SPSS, Chicago, IL) was used for all statistical analyses. When $P$ was $<0.05$, the differences between the groups were considered statistically significant.

\section{RESULTS}

A total of 245 consecutive patients who underwent cardiac surgery were assessed. The ages of the patients ranged from 80 to 93 years (median 81 years). It was found that 28 patients $(11.4 \%)$ included in the study were 85 years of age or older; five patients (2\%) were over 90 years old. Sixty-one patients (24.9\%) had left ventricular ejection fractions (LVEFs) <50\% (23 patients had LVEF <35\%). Twenty-one patients (8.6\%) had a history of cerebrovascular events, and five of them had a persistent minor neurological deficit. Four patients (1.6\%) had previously undergone cardiac surgery. Twenty-six patients (10.6\%) were operated on under emergency conditions, and two of them (0.8\%) had acute aortic dissections. The baseline characteristics of the study patients and early postoperative outcomes are summarized in Table 1.

Isolated cardiac procedures were performed on 203 patients (82.8\%), whereas concomitant procedures were performed on 42 patients (17.2\%). Seven patients (2.9\%) had more than three concomitant procedures. Perfusion time and aortic crossclamp time analyses were performed only for on-pump cardiac procedures $(n=193)$, the mean aortic cross-clamp time was $70 \pm 34.3$ (19-242) minutes, and the mean total perfusion time was $111.1 \pm 52.3$ (38-480) minutes. Isolated on-pump coronary artery bypass graft (CABG) surgery $(n=116,47.3 \%)$ was the most frequently performed surgical procedure. Valve operations were performed on 73 patients (29.8\%), and valve replacements $(n=58)$ were performed rather than valve repair $(n=14)(79.5 \%$ to $20.5 \%$, respectively). The surgical procedures performed and the in-hospital mortality rates are summarized in Table 2.

\section{Subgroup Analyses}

The data of 168 patients who underwent CABG surgery are shown in Table 3. Patients were categorized as off-pump CABG and on-pump CABG. Diabetes mellitus and previous cerebrovascular event rates were significantly high in the on-pump group. In the on-pump group, more vessels were bypassed during surgery than those in the off-pump group. The mean perfusion time for patients who had isolated on-pump CABG was $97.1 \pm 30.8$ minutes, and the mean ischemic time was $60.7 \pm 26.9$ minutes. Eighteen out of 168 patients (10.7\%) died during the in-hospital period. Analyses revealed that both techniques (on-pump CABG and off-pump CABG) had similar outcomes in the early postoperative period. The survival curves for each group are shown in Figure 1. On-pump CABG had better outcomes, but the difference was not statistically significant in the Kaplan-Meier analysis.

In this study, 32 patients had undergone isolated valve surgery. The mean perfusion time and the mean ischemic time were $100.9 \pm 34.6$ and $63.7 \pm 27.6$ minutes, respectively, in the isolated aortic valve procedures. All isolated aortic valve procedures were mechanical valve replacements. The mean perfusion and ischemic times for the mitral valve procedures, on the other hand, were $76.8 \pm 12.7$ and $53.3 \pm 101$ minutes, respectively. Valve repairs were performed in four (80\%) patients who had undergone isolated mitral valve surgeries. The type of valve surgery technique was not related to in-hospital mortality (in-hospital mortality rate was 20\% in the repair group, whereas it was $17.9 \%$ in the mechanical valve group) $(P>0.05)$.

\section{Survival Analysis and Predictors of Mortality}

In our study, the overall in-hospital mortality rate was 15.1\%. Age $\geq 85$ years (adjusted OR 6.08, 95\% Cl 2.77-11.3, $P=0.03$ ), chronic kidney disease (adjusted OR 2.46, 95\% Cl 1.17-2.75, 
Table 1. Baseline characteristics and postoperative outcomes of the study population $(n=245)$.

\section{Preoperative data}

\begin{tabular}{|c|c|}
\hline Age (years), mean \pm SD (min-max) & $81.6 \pm 2.4(80-93)$ \\
\hline Male gender, n (\%) & $151(6.6)$ \\
\hline $\mathrm{BMI}\left(\mathrm{kg} / \mathrm{m}^{2}\right)$ mean $\pm \mathrm{SD}$ (min-max) & $26.7 \pm 4.5(16-40)$ \\
\hline Obesity, n (\%) & $28(11.4)$ \\
\hline Hypertension, n (\%) & $135(55.1)$ \\
\hline Diabetes mellitus, n (\%) & $75(30.6)$ \\
\hline COPD, n (\%) & $33(13.5)$ \\
\hline Renal insufficiency, n (\%) & $17(6.9)$ \\
\hline Cerebrovascular event, n (\%) & $21(8.6)$ \\
\hline Previous cardiac surgery, n (\%) & $4(1.6)$ \\
\hline \multicolumn{2}{|l|}{ Preoperative rhythm, n (\%) } \\
\hline Sinus rhythm & $204(83.3)$ \\
\hline Atrial fibrillation/flutter & $36(14.7)$ \\
\hline Pacemaker & $5(2)$ \\
\hline 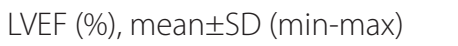 & $52.1 \pm 10.9(20-70)$ \\
\hline
\end{tabular}

\section{Postoperative data}

\begin{tabular}{|c|c|}
\hline First-day drainage (ml), mean \pm SD (min-max) & $500 \pm 450(100-1950)$ \\
\hline Extubation time (hours), mean $\pm S D$ (min-max) & $14 \pm 8(6-96)$ \\
\hline Respiratory failure, n (\%) & $34(13.9)$ \\
\hline Massive bleeding, n (\%) & $17(6.9)$ \\
\hline Tamponade, n (\%) & $3(1.2)$ \\
\hline Sepsis, n (\%) & $11(4.5)$ \\
\hline Hemodialysis, n (\%) & $14(5.7)$ \\
\hline Rhythm disturbance, n (\%) & $52(21.2)$ \\
\hline Length of ICU stays (days), mean \pm SD (min-max) & $3 \pm 2(1-39)$ \\
\hline Length of hospital stays (days), mean \pm SD (min-max) & $8 \pm 6(4-60)$ \\
\hline
\end{tabular}

$\mathrm{BMI}=$ body mass index; $\mathrm{COPD}=$ chronic obstructive pulmonary disease; LVEF=left ventricular ejection fraction; ICU=intensive care unit

$P=0.003$ ), chronic obstructive pulmonary disease (adjusted OR 2.29, 95\% Cl=1.92-8.06, $P=0.02$ ) and emergency surgery (adjusted $\mathrm{OR} 13.80,95 \% \mathrm{Cl} 1.85-42.32, P=0.01$ ) have a strong association with in-hospital mortality in the multivariate analysis. The in-hospital mortality rate after elective procedures was 10\% and $57.7 \%$ in the patient group operated under emergency conditions. The mean follow-up was $5.4 \pm 3.7$ (0.5-15) years and the median survival time was $4.4 \pm 0.3$ (3.1-5.6) years for all participants $(n=245)$. Actuarial survival rates were shown in Table 4. The median survival time, however, was 5.2 \pm 0.6 (4-6.4) years for 219 patients who had been operated on under elective conditions (Figure 2).

\section{DISCUSSION}

After cardiac operations, octogenarians have worse outcomes than younger patients and in-hospital mortality rates have been found to increase up to $24 \%[5,11,13,15]$. Recent studies conducted in developed countries, however, have revealed that the mortality rates of these patients have decreased to $8.1 \%^{[10,13]}$. On the other hand, in-hospital mortality rates were reported between $12.5 \%$ and $16.8 \%$ in recent studies carried out with Turkish patients ${ }^{[14,15]}$. In our study, the in-hospital mortality rate in electively operated cases was $10 \%$ and $7 \%$ in the isolated cardiac procedures, performed electively. These results are comparable to those of recent North American and European studies ${ }^{[2,3,7-10,13,15] \text {. }}$ 
Table 2. In-hospital survival outcomes (stratified by procedures).

\begin{tabular}{|c|c|c|}
\hline & Total $(n=245)$ & Elective $(n=219)$ \\
\hline Mortality, n (\%) & $37(15.1)$ & $22(10)$ \\
\hline Isolated procedures, n (\%) & 25/203 (12.3) & $13(7.1)$ \\
\hline Off-pump CABG & $4 / 52(7.7)$ & $4(8.2)$ \\
\hline On-pump CABG & $14 / 116(12.1)$ & $6(5.7)$ \\
\hline AV surgeries & $5 / 27(18.5)$ & $2(8.3)$ \\
\hline MV surgeries & $1 / 5(20)$ & $1(33)$ \\
\hline Thoracic aortic surgeries & $1 / 3(33.3)$ & - \\
\hline Concomitant procedures, n (\%) & $12 / 42(28.6)$ & $9(25)$ \\
\hline$C A B G+A V$ & $5 / 23(38.5)$ & $4(36.4)$ \\
\hline$C A B G+M V$ & $3 / 10(30)$ & $2(22.2)$ \\
\hline Double-valve surgeries & $1 / 5(20)$ & $1(20)$ \\
\hline $\mathrm{AV}+$ ascending aortic surgeries & - & - \\
\hline Three and more procedures & $3 / 7(42.9)$ & $2(40)$ \\
\hline \multicolumn{3}{|l|}{ Valve interventions, n (\%) } \\
\hline Repair & $4 / 15(26.7 \%)$ & $2 / 10(20)$ \\
\hline Replacement & $14 / 58(24.1 \%)$ & 10/52 (19.2) \\
\hline
\end{tabular}

$\mathrm{AV}=$ aortic valve; $\mathrm{CABG}=$ coronary artery bypass graft; $\mathrm{MV}=$ mitral valve

Table 3. Isolated coronary artery bypass graft surgery patients.

\begin{tabular}{|c|c|c|c|}
\hline & On-pump CABG & Off-pump CABG & $P$-value \\
\hline Patients, n (\%) & $116(69)$ & $52(31)$ & - \\
\hline Age (years), mean $\pm S D$ & $81.3 \pm 2.3$ & $81.2 \pm 1.8$ & NS \\
\hline Male gender, n (\%) & $71(61.2)$ & $40(76.9)$ & NS \\
\hline LITA, n (\%) & $85(73.3)$ & $36(69.2)$ & NS \\
\hline Graft number, mean \pm SD (min-max) & $3 \pm 1(1-6)$ & $2 \pm 1(1-4)$ & $<0.001$ \\
\hline Diabetes mellitus, n (\%) & $37(32.5)$ & $8(16.7)$ & 0.04 \\
\hline Hypertension, n (\%) & $63(55,3)$ & $25(51)$ & NS \\
\hline Renal insufficiency, n (\%) & $6(5.2)$ & $3(5.8)$ & NS \\
\hline COPD, n (\%) & $12(10.3)$ & $6(11.5)$ & NS \\
\hline Previous CVE, n (\%) & $15(12.9)$ & $1(1.9)$ & 0.01 \\
\hline Previous cardiac surgery, n (\%) & $1(0.9)$ & $0(0)$ & NS \\
\hline LVEF (\%), mean \pm SD & $52.6 \pm 10$ & $48.8 \pm 11$ & NS \\
\hline Emergency operation, n (\%) & $10(8.6)$ & $3(5.8)$ & NS \\
\hline First day drainage $(\mathrm{ml})$, mean $\pm \mathrm{SD}$ & $546.1 \pm 277$ & $572 \pm 386$ & NS \\
\hline Length of ICU stay (days), mean \pm SD & $3.3 \pm 2.4$ & $2.3 \pm 1.5$ & 0.057 \\
\hline Length of hospital stay (days), mean \pm SD & $10.2 \pm 5.5$ & $9.2 \pm 6.5$ & NS \\
\hline In-hospital mortality, n (\%) & $4(7.7)$ & $14(12.1)$ & NS \\
\hline
\end{tabular}

$\mathrm{CABG}=$ coronary artery bypass graft; $\mathrm{COPD}=$ chronic obstructive pulmonary disease; $\mathrm{CVE}=$ cerebrovascular event; $\mathrm{ICU}=$ intensive care unit; LITA=left internal thoracic artery; LVEF=left ventricular ejection fraction; NS=nonsignificant 


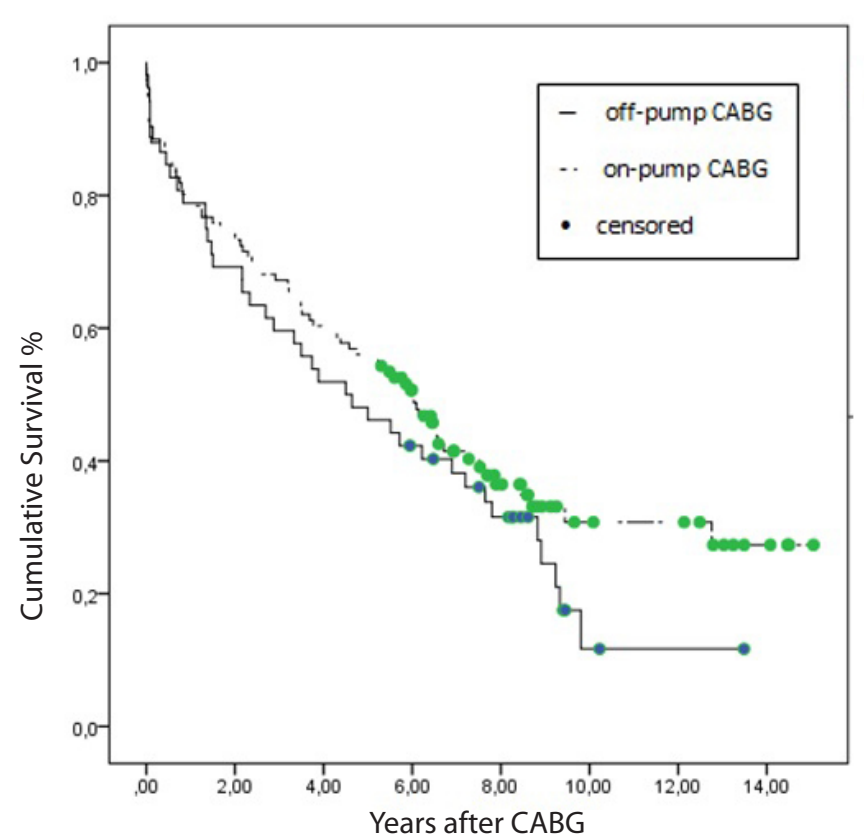

Fig. 1 - Survival curves of patients who underwent isolated coronary artery bypass surgery (7.1 years for on-pump CABG and 5.3 years for off-pump $C A B G$, log-rank $>0.05) C A B G=$ coronary artery bypass graft.

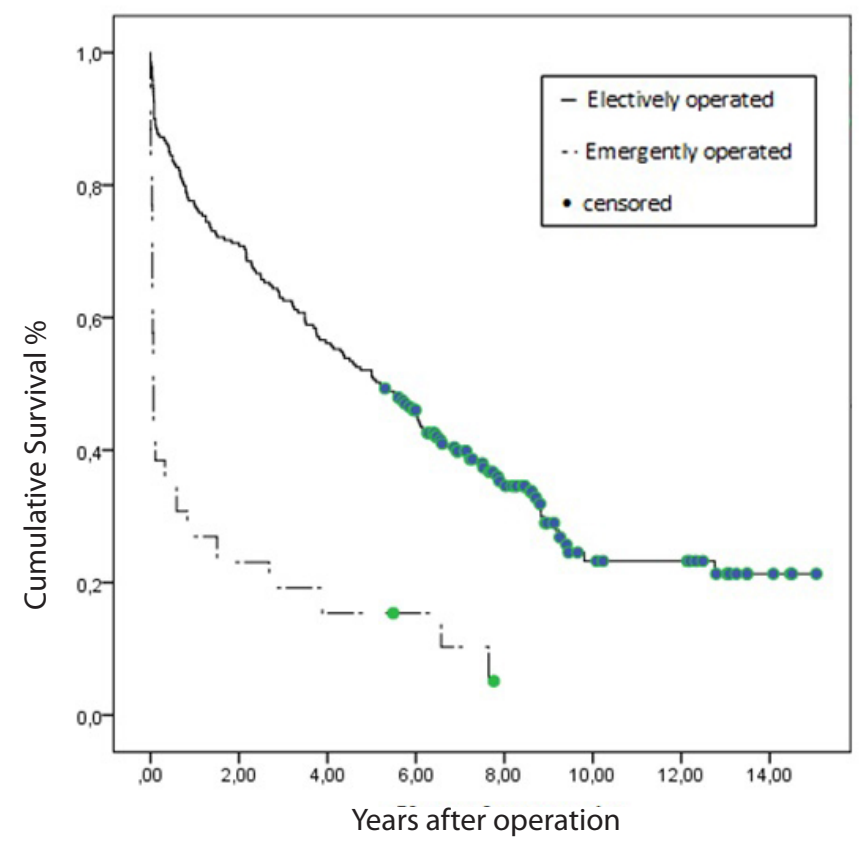

Fig. 2 - Survival curves of electively operated and emergently operated cases $(5.2 \pm 0.6$ years and $0.06 \pm 0.01$ years, respectively, log-rank <0.001).

Table 4. Actuarial survival rates at 1,5 and 10 years.

\begin{tabular}{|c|c|c|c|c|}
\hline & & $1^{\text {st }}$ year & $5^{\text {th }}$ year & $10^{\text {th }}$ year \\
\hline & All patients & & & \\
\hline Total & $(n=245)$ & $176(72 \%)$ & $118(48 \%)$ & $18(21 \%)$ \\
\hline \multirow[t]{2}{*}{ Elective cases } & $(n=219)$ & $169(77 \%)$ & $114(52 \%)$ & $18(24 \%)$ \\
\hline & Off-pump CABG & & & \\
\hline Total & $(n=52)$ & $41(79 \%)$ & $25(48 \%)$ & $2(13 \%)$ \\
\hline \multirow[t]{2}{*}{ Elective cases } & $(n=49)$ & $38(78 \%)$ & $24(49 \%)$ & $2(14 \%)$ \\
\hline & On-pump CABG & & & \\
\hline Total & $(n=116)$ & $92(79 \%)$ & $65(56 \%)$ & $12(31 \%)$ \\
\hline \multirow[t]{2}{*}{ Elective cases } & $(n=106)$ & $90(85 \%)$ & $63(59 \%)$ & $12(33 \%)$ \\
\hline & AV surgeries & & & \\
\hline Total & $(n=27)$ & $16(59 \%)$ & $11(41 \%)$ & $2(16 \%)$ \\
\hline \multirow[t]{2}{*}{ Elective cases } & $(n=24)$ & $16(67 \%)$ & $11(46 \%)$ & $2(17 \%)$ \\
\hline & MV surgeries & & & \\
\hline Total & $(n=5)$ & $2(40 \%)$ & $1(20 \%)$ & \\
\hline Elective cases & $(n=3)$ & $2(67 \%)$ & $1(33 \%)$ & \\
\hline
\end{tabular}


In the present study, to avoid patient selection bias, we analyzed all octogenarian patients who had undergone cardiac surgery at our hospital. The overall in-hospital mortality rate was $15.1 \%$ in our study. We found that these patients had increased mortality rates, especially when they were operated on in emergency circumstances and concomitant procedures. Our hospital is one of the tertiary care services in the national health care system, and we cannot refuse patients at risk. We treat plenty of emergency cases from all over the country, and this situation might have affected our overall mortality rates. In our study, patients operated on in emergency conditions had an increased in-hospital mortality rate of $57.7 \%$. Most studies concluded that patients who had undergone operations in emergency situations had in-hospital mortality rates as high as $40 \%[2,5,11,12,15]$.

In subgroup analyses, the in-hospital mortality rate of the patients who had undergone isolated CABG was $10.7 \%$. This rate decreased to $6.5 \%$ in elective cases, and was comparable to that in major studies, which defined rates between $4.1 \%$ and $13 \%[7,10,13,15]$. Latest studies have shown that isolated aortic valve surgeries had in-hospital mortality rates between $5.7 \%$ and $8.5 \%$ in the octogenarian group. In our study, we found higher rates of $18.5 \%$, but decreased to $8.3 \%$ in elective cases, which is similar to that of other studies ${ }^{[2,8,12]}$. Previous studies revealed that isolated mitral valve procedures had higher mortality rates than aortic valve procedures and CABG. Mortality rates from mitral valve surgeries in patients older than 80 years have been reported to be between $16.7 \%$ and $25 \%[2,9]$. Similarly, in this study, this rate was found to be $20 \%$; this was higher than the mortality rates of CABG and aortic valve operations.

In developed countries, the median survival time in octogenarians varied between 5.5 and 7.4 years after cardiac operations ${ }^{[9,10]}$. Although life expectancy for people aged 80 in Turkey is similar to that for people of similar age in developed countries, in our study, the mean survival time was $4.4 \pm 0.3$ years for all participants, and it was lower than that obtained in other studies $^{[9,10,16]}$. Our outcomes of in-hospital mortality rates were satisfactory in elective cases, but the median survival time of these patients was still $5.2 \pm 0.6$ years. Compared to the previously published Brazilian study, which focused on isolated CABG in octogenarian population, despite the fact that the 1-year survival rates of our population was similar (80.6\% and $79.4 \%)$, the 5-year survival rates of our patients were worse than that report $(53.8 \%$ and $65.2 \%)^{[17]}$. A recent study has revealed that Turkish octogenarians living in urban areas have worse functional statuses than their Mexican and American counterparts ${ }^{[6]}$. Another community-based study suggested that Turkish octogenarians living in rural areas had functional statuses comparable to those in other developing countries $^{[18]}$. However, due to the unbalanced distribution of cardiac centers in our country, they might have experienced difficulties in reaching satisfactory cardiac care, especially in cardiac rehabilitation and maintaining adequate international normalized ratio when using vitamin $\mathrm{K}$ antagonists. Besides, the inappropriate use of drugs, especially nonsteroidal anti-inflammatory drugs in chronic heart failure, was observed in the elderly Turkish population twice as high as that in developed countries ${ }^{[19]}$. These circumstances might have affected our long-term outcomes.
This study has several limitations due to the retrospective design of the study. Although we have done a detailed analysis of the risk profiles with defined comorbidities of the patient groups, there are probably still unmeasured variables. In particular, the insufficiency of in-hospital data for frailty assessment is one of the major deficiencies of the study. Finally, our main interest was to investigate the long-term outcomes of a challenging age group after cardiac surgery. Despite the heterogeneous study population, these results could reflect the current scenario of patients undergoing cardiac surgery.

Finally, octogenarians have satisfactory outcomes after openheart surgery when operated electively. However, outcomes are getting worse in cases of emergency and long-term follow-up.

\section{No financial support.}

No conflict of interest.

\section{Authors' roles \& responsibilities}

MA Substantial contributions to the conception or design of the work; or the acquisition, analysis, or interpretation of data for the work; drafting the work or revising it critically for important intellectual content; agreement to be accountable for all aspects of the work in ensuring that questions related to the accuracy or integrity of any part of the work are appropriately investigated and resolved; final approval of the version to be published

DG Substantial contributions to the conception or design of the work; or the acquisition, analysis, or interpretation of data for the work; drafting the work or revising it critically for important intellectual content; agreement to be accountable for all aspects of the work in ensuring that questions related to the accuracy or integrity of any part of the work are appropriately investigated and resolved; final approval of the version to be published

TÖ Substantial contributions to the conception or design of the work; or the acquisition, analysis, or interpretation of data for the work; drafting the work or revising it critically for important intellectual content; agreement to be accountable for all aspects of the work in ensuring that questions related to the accuracy or integrity of any part of the work are appropriately investigated and resolved; final approval of the version to be published

ÖAY Substantial contributions to the conception or design of the work; or the acquisition, analysis, or interpretation of data for the work; drafting the work or revising it critically for important intellectual content; agreement to be accountable for all aspects of the work in ensuring that questions related to the accuracy or integrity of any part of the work are appropriately investigated and resolved; final approval of the version to be published

Substantial contributions to the conception or design of the work; or the acquisition, analysis, or interpretation of data for the work; drafting the work or revising it critically for important intellectual content; agreement to be accountable for all aspects of the work in ensuring that questions related to the accuracy or integrity of any part of the work are appropriately investigated and resolved; final approval of the version to be published 
MKK Substantial contributions to the conception or design of the work; or the acquisition, analysis, or interpretation of data for the work; drafting the work or revising it critically for important intellectual content; agreement to be accountable for all aspects of the work in ensuring that questions related to the accuracy or integrity of any part of the work are appropriately investigated and resolved; final approval of the version to be published

\section{REFERENCES}

1. HeW, Goodkind D, Kowal P, editors. An aging World: 2015. Washington (DC): United States Census Bureau; 2016. p.138-49.

2. Kolh P, Kerzmann A, Lahaye L, Gerard P, Limet R. Cardiac surgery in octogenarians; peri-operative outcome and long-term results. Eur Heart J. 2001;22(14):1235-43. doi:10.1053/euhj.2000.2443.

3. Diegeler A, Autschbach R, Falk V, Walther T, Gummert J, Mohr FW, et al. Open heart surgery in the octogenarians--a study on long-term survival and quality of life. Thorac Cardiovasc Surg. 1995;43(5):265-70. doi:10.1055/s-2007-1013225.

4. Canbaz S, Sünter AT, Dabak S, Pekşen Y. The prevalence of chronic diseases and quality of life in elderly people in Samsun. Turk J Med Sci. 2003;33(5):335-40.

5. Aksoydan, E. Are developing countries ready for ageing populations? An examination on the socio-demographic, economic and health status of elderly in Turkey. Turk Geriatri Derg. 2009;12(9):102-9.

6. Bahat G, Tufan F, Bahat Z, Aydin Y, Tufan A, AkpinarTS, et al. Assessments of functional status, comorbidities, polypharmacy, nutritional status and sarcopenia in Turkish community-dwelling male elderly. Aging Male. 2013;16(2):67-72. doi:10.3109/13685538.2013.771329.

7. Stamou SC, Dangas G, Dullum MK, Pfister AJ, Boyce SW, Bafi AS, et al. Beating heart surgery in octogenarians: perioperative outcome and comparison with younger age groups. Ann Thorac Surg. 2000;69(4):11405. doi:10.1016/s0003-4975(99)01430-7.

8. Chiappini B, Camurri N, Loforte A, Di Marco L, Di Bartolomeo R, Marinelli
G. Outcome after aortic valve replacement in octogenarians. Ann Thorac Surg. 2004;78(1):85-9. doi:10.1016/j.athoracsur.2003.12.060.

9. Craver JM, Puskas JD, Weintraub WW, Shen Y, Guyton RA, Gott JP, et al. 601 octogenarians undergoing cardiac surgery: outcome and comparison with younger age groups. Ann Thorac Surg. 1999;67(4):110410. doi:10.1016/s0003-4975(99)00154-x.

10. Likosky DS, Dacey LJ, Baribeau YR, Leavitt BJ, Clough R, Cochran RP, et al. Long-term survival of the very elderly undergoing coronary artery bypass grafting. Ann Thorac Surg. 2008;85(4):1233-7. doi:10.1016/j. athoracsur.2007.12.066.

11. Edmunds LH Jr, Stephenson LW, Edie RN, Ratcliffe MB. Open-heart surgery in octogenarians. N Engl J Med. 1988;319(3):131-6. doi:10.1056/ NEJM198807213190302.

12. de Vincentiis C, Kunkl AB, Trimarchi S, Gagliardotto P, Frigiola A, Menicanti $L$, et al. Aortic valve replacement in octogenarians: is biologic valve the unique solution? Ann Thorac Surg. 2008;85(4):1296-301. doi:10.1016/j. athoracsur.2007.12.018.

13. Alexander KP, Anstrom KJ, Muhlbaier LH, Grosswald RD, Smith PK, Jones $\mathrm{RH}$, et al. Outcomes of cardiac surgery in patients > or $=80$ years: results from the National cardiovascular network. J Am Coll Cardiol. 2000;35(3):731-8. doi:10.1016/s0735-1097(99)00606-3.

14. Kara I, Ay Y, Köksal C, Aydın C, Yanartaş M, Yıldııım T. The quality of life after cardiac surgery in octogenarians and evaluation of its early and mid-term results. Anadolu Kardiyol Derg. 2012;12(4):352-8.

15. Ozen A, Unal EU, Songur M, Kocabeyoglu SS, Hanedan O, Yilmaz M, et al. Coronary artery bypass grafting in the octogenarians: should we intervene, or leave them be? J Geriatr Cardiol. 2015;12(2):147-52. doi:10.11909/j.issn.1671-5411.2015.02.005.

16. Single age life table for Turkey by sex. Turkish Statistical Institute data 2013-2017 [cited 2019 May 28]. Available at: http://tuik.gov.tr/UstMenu. do?metod=temelist

17. Pivatto Júnior F, Valle FH, Pereira EM, Aguiar FM, Henn NT, Behr PE, et al. Long-term survival of octogenarian patients submitted to isolated coronary artery bypass graft surgery. Rev Bras Cir Cardiovasc. 2011;26(1):21-6. doi:10.1590/s0102-76382011000100007.

18. Çakmur H. Frailty among elderly adults in a rural area of Turkey. Med Sci Monit. 2015;21:1232-42. doi:10.12659/MSM.893400.

19. Cibik B, Şahin EM, Kilinçarslan MG. A population-based study: the appropriateness of drug use in the elderly according to beers criteria. Turk Geriatri Derg. 2018;2(1):1-15. doi:10.31086tjgeri.2018137962. 